\title{
Impact of vehicle fleet characteristics on ambient PM concentrations during rainy season at Farm Gate (CAMS-2) in Dhaka
}

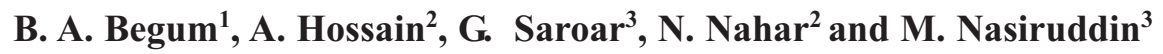 \\ ${ }^{1}$ Chemistry Division, Atomic Energy Centre, P.O. Box 164, Dhaka-1000 \\ ${ }^{2}$ Chemistry Department, Jahangirnagar University \\ ${ }^{3}$ Clean Air \& Sustainable Environment project, DoE, Dhaka
}

\begin{abstract}
The impact of vehicle fleet characteristics on ambient particulate matters (both $\mathrm{PM}_{2.5}$ and $\mathrm{PM}_{10}$ ) concentrations during the rainy season was investigation. Sampling was corriedout at the continuous air monitoring station (CAMS-2) at the Farm Gate site, a location near a major traffic intersection. It was observed from the analysis, that the $\mathrm{PM}_{2.5}$ concentrations were not varying so much between day and night time. This might be due to the rainfall and high humidity during these days. As the $\mathrm{PM}_{2.5}$ is less, so $\mathrm{BC} / \mathrm{PM}_{2.5}$ becomes high compared to winter season. Therefore $\mathrm{PM}_{2.5} / \mathrm{PM}_{10}$ ratio is also less compared to winter time, as $\mathrm{PM}_{2.5}$ is the part of $\mathrm{PM}_{10}$. The black carbon (BC) value is less during this period compared to winter due to both local and meteorological effect. It was also found that although there was heavy rainfall on 13 July 2010, the PM concentration is also high. It may be due to the contribution of sea salt to PM.
\end{abstract}

Keywords: $\mathrm{PM}_{2.5}, \mathrm{PM}_{10}, \mathrm{CAMS}-2$

\section{Introduction}

Dhaka is the eighth largest city in the world. Rapid urban population growth is projected to reach approximately 20 million by the year 2020. Vehicular emissions are one of the major sources of pollution in Dhaka where the vehicle fleet characteristics are different in the day and nighttime. To understand impact of fleet characteristics on particulate matter (PM) concentration, sampling was conducted (both $\mathrm{PM}_{10}$ and $\mathrm{PM}_{2.5}$ fractions) from 5 - 19 July, 2010 at the continuous air monitoring station (CAMS-2) at the Farm Gate site, a location near a major traffic intersection. In recent years, high circulations of commercial vehicles (primarily buses and cars) and small industries (primarily brick kilns) have contributed to increase levels of air pollution, especially PM, in and around cities of Bangladesh. Fine particulate matter with aerodynamic diameter less than $2.5 \mathrm{~m}$ is a widespread air pollution problem. In Dhaka, Bangladesh, the daily average of $\mathrm{PM}_{2.5}$ levels usually exceeds the Bangladesh National Ambient Air Quality Standard (NAAQS) of $65 \mu \mathrm{g} / \mathrm{m}^{3}$ in winter although they meet the requirements during the monsoon season. As a result, the annual average can never comply with the National Standard of $15 \mu \mathrm{g} / \mathrm{m}^{3}$. Previous studies of Dhaka air quality showed major fractions of the $\mathrm{PM}_{2.5}$ is Black Carbon (BC) (Begum et. al., 2010a, Begum et. al.,
2004). There are no coal- or oil-fired power plants in and around Dhaka. Therefore, the emission of BC and sulfur comes from diesel (heavy duty vehicles), household solid fuel combustion, and brick kilns where coal is used as fuel. Public buses, private cars, and 3-wheeled taxis, which mainly run during daytime, are operated on compressed natural gas (CNG). Heavy-duty diesel vehicles ply the roads primarily during the night (10 PM to $8 \mathrm{AM}$ ) because of restrictions imposed to reduce traffic congestion. It has been found that about $85 \%$ of total vehicle fleet (Begum et. al., 2012) during the daytime in Dhaka is private cars. The densities of cars are high on weekdays. On the other hand about $18 \%$ of total vehicles are trucks that run through this area at night. Because of frequent power failures, diesel-run generators are used extensively to meet the electricity demand. These diesel-run generators, heavy-duty vehicles and brick kilns emit carbonaceous particles, which are important contributors to ambient $\mathrm{PM}_{2.5}$ concentrations. On the other hand, due to the geographical position, there are also transboundary impact (both natural and anthropogenic source)(Begum et. al., 2011b) during the dry season when wind mainly comes from the north and northwest direction.

\footnotetext{
*Corresponding author. e-mail: bilkisab@dhaka.net
} 
Bangladesh has a climate of tropical monsoon, mild winter (October to February), hot, humid summer (March to May) and humid warm rainy monsoon (June to October).

It rains mostly during June to October. In the present study the sampling were done during July 5-19, 2010. The aim of this study was to understand the pollution characteristics and to the compare the results with those reported during dry season.

\section{Materials and methods}

\section{Sampling}

The Air Metrics MiniVol sampler developed jointly by the U.S. Environmental Protection Agency (EPA) and the Lane Regional Air Pollution Authority was used for both $\mathrm{PM}_{10}$ and $\mathrm{PM}_{2.5}$ sampling (Baldauf et. al., 2001) from Farm Gate site (Fig. 1) in Dhaka city. Farm Gate is a hot spot site due to the proximity of several major roadways intersection and large numbers of vehicles plying through the area (Begum et. al., 2005). The site is surrounded by commercial and semi industrial areas.

The samplers were placed on the flat roof of the guardhouse of Bangladesh Agricultural Research Council (BARC). This location also houses the second continuous air monitoring station (CAMS) in Dhaka. The MiniVols were programmed to sample at $5 \mathrm{lpm}$ through $\mathrm{PM}_{10}$ and $\mathrm{PM}_{2.5}$ particle size separators (impactors) and then through $2 \mathrm{~m}$ pore Teflon filters. The actual flow rate should be $5 \mathrm{lpm}$ at ambient conditions for proper size fractionation. To ensure a constant flow of 5 lpm through the size separator at different air temperatures

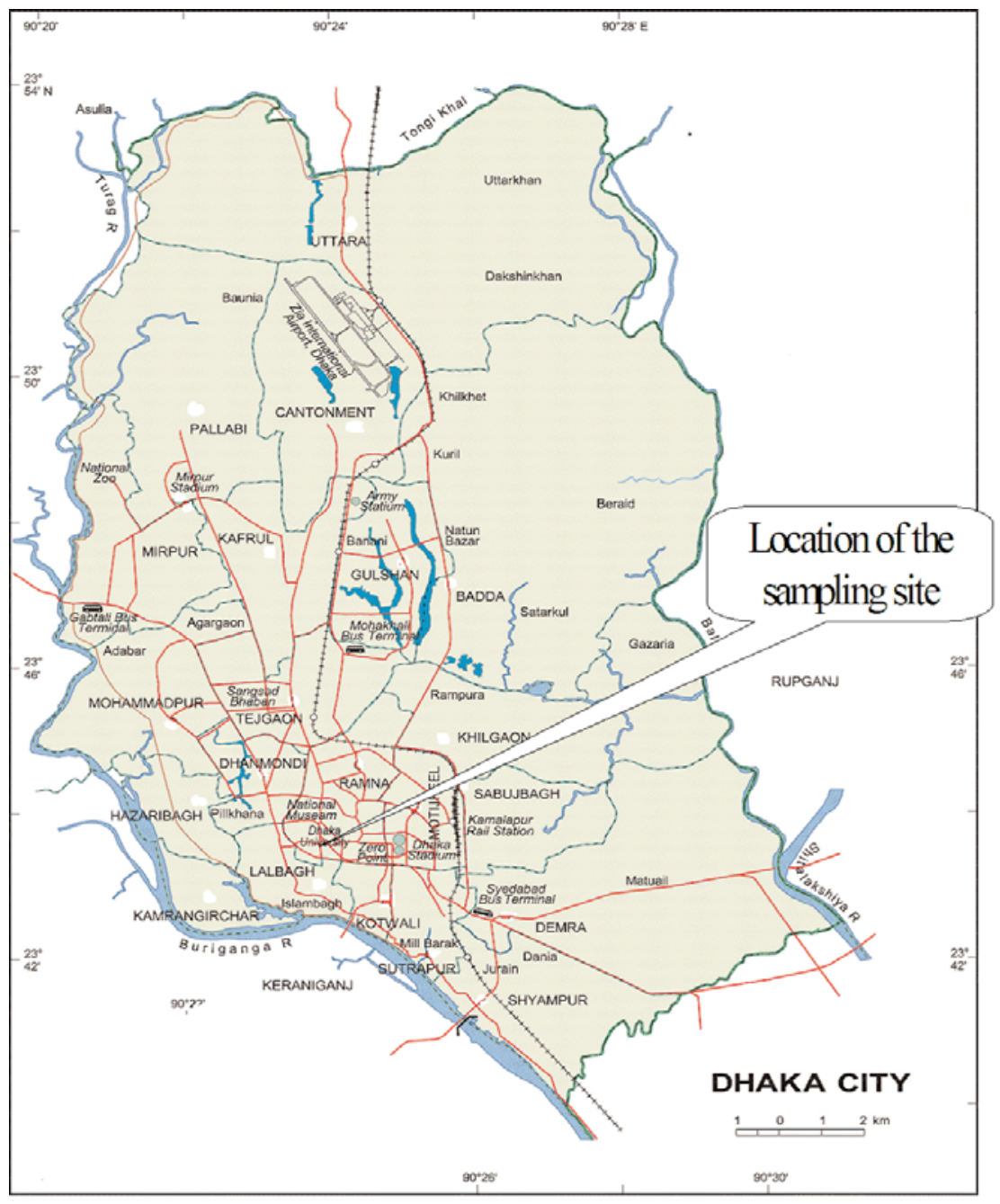

Fig. 1. Map of sampling location 
and ambient pressures, the sampler flow rates were adjusted for the ambient conditions at the sampling site. The MiniVol sampler was positioned with the intake upward and located in an unobstructed area at least $30 \mathrm{~cm}$ from any obstacle to air flow and the sampler inlet was placed at a height of $10 \mathrm{~m}$ above ground level for the Farm Gate area. The intake nozzle of the sampler at the Farm Gate location was about $5 \mathrm{~m}$ away from the main road. $\mathrm{PM}_{10}$ and $\mathrm{PM}_{2.5}$ were collected simultaneously from 8 am to $6 \mathrm{pm}$ and $8 \mathrm{pm}$ to 6 am with two MiniVol samplers. The inlets of the samplers were kept $45 \mathrm{~cm}$ apart from each other.

The sampling protocol was continued for fifteen consecutive days starting from July 05 to July 19, 2010. The conditioned clean filters were loaded to respective filter holder assembly at the CAMS- 2 conditioning room and were brought to sampling site in separate clean polyethylene bags at each effective sampling day. After sampling, the filter holder assemblies (keeping the exposed filters inside) were brought to the conditioning room of AECD directly from the sampling site for conditioning and PM retrieval. Care was taken in transporting the exposed filter holder assemblies, so that there should be no PM loss.

\section{Traffic volume at the sampling site}

A traffic survey was conducted by manual counting of vehicles in the Farm Gate corridor in front of the sampling site on selected days during the present study to understand correlation between PM concentration and traffic volume. It was observed that the private cars are the main motorized vehicles $(80 \%$ of the total vehicles) plying along this corridor. Some buses (large and medium) are also run through the roadways. Table I summarizes the day time traffic counts and Table II summarizes the night time traffic counts. Tables I and II show that heavy duty diesel trucks operate 17 times more frequently at night than during the day. Among the bus and minibuses, only a few buses run on CNG and most of the buses and minibuses have diesel engines.

\section{Meteorological conditions}

In Bangladesh, the climate is characterized by high temperatures, high humidity most of the year and distinctly marked seasonal variation of precipitation. According to meteorological condition, the year can be divided into four seasons, premonsoon (March-May), monsoon (June-September), postmonsoon (October-November) and winter (DecemberFebruary) (Salam et. al., 2003). As the dispersion of PM strongly depends on the wind speed and direction the meteorological data for dates of samples collection was collected from the nearby meteorological station, which is located about 2 kilometers east of the sampling sites. The sampling was done in early pre-monsoon period.

\section{Measurement of PM mass and black carbon (BC)}

PM mass was measured in the Chemistry Lab of the Atomic Energy Centre, Dhaka (AECD). The $\mathrm{PM}_{10}$ and $\mathrm{PM}_{2.5}$ samples were determined by weighing the filters before and after exposure using a microbalance (Begum et. al., 2006). The filters

Table I. Average number of different motor vehicles plying at Farm Gate during daytime

\begin{tabular}{lcccc}
\hline Date & Bus \& Minibus & Private car \&CNG & Motor Cycle & Truck \\
\hline $02 / 17 / 2010$ & 2912 & 63345 & 6105 & 540 \\
$02 / 18 / 2010$ & 2898 & 64350 & 5998 & 612 \\
$02 / 19 / 2010$ & 2962 & 43534 & 3876 & 804 \\
$02 / 20 / 2010$ & 2789 & 43790 & 4586 & 693 \\
$02 / 21 / 2010$ & 2898 & 50180 & 6233 & 854 \\
$02 / 22 / 2010$ & 3080 & 66712 & 6192 & 520 \\
$02 / 23 / 2010$ & 2848 & 65958 & 6630 & 912 \\
$02 / 24 / 2010$ & 2880 & 63145 & 6232 & 550 \\
$02 / 25 / 2010$ & 3007 & 62151 & 6130 & 584 \\
$02 / 26 / 2010$ & 2919 & 41237 & 3979 & 650 \\
$02 / 27 / 2010$ & 2990 & 44321 & 5110 & 852 \\
$02 / 28 / 2010$ & 3123 & 62328 & 6980 & 673 \\
$03 / 01 / 2010$ & 2960 & 61710 & 7210 & 830 \\
$03 / 02 / 2010$ & 3452 & 62130 & 7584 & 678 \\
$03 / 03 / 2010$ & 3323 & 61130 & 7019 & 590 \\
\hline
\end{tabular}


Table II. Average number of different motor vehicles plying at Farm Gate during night time

\begin{tabular}{lcccc}
\hline Date & Bus \& Minibus & Private car \&CNG & Motor Cycle & Truck \\
\hline $02 / 17 / 2010$ & 850 & 12345 & 876 & 2890 \\
$02 / 18 / 2010$ & 1007 & 11987 & 987 & 3060 \\
$02 / 19 / 2010$ & 865 & 11230 & 905 & 3790 \\
$02 / 20 / 2010$ & 890 & 10980 & 926 & 3346 \\
$02 / 21 / 2010$ & 896 & 11675 & 878 & 3416 \\
$02 / 22 / 2010$ & 953 & 15120 & 698 & 3468 \\
$02 / 23 / 2010$ & 904 & 11580 & 1400 & 2886 \\
$02 / 24 / 2010$ & 839 & 9879 & 1123 & 2918 \\
$02 / 25 / 2010$ & 870 & 13980 & 819 & 3012 \\
$02 / 26 / 2010$ & 890 & 14546 & 907 & 3310 \\
$02 / 27 / 2010$ & 911 & 13345 & 784 & 4260 \\
$02 / 28 / 2010$ & 895 & 14789 & 980 & 3980 \\
$03 / 01 / 2010$ & 885 & 12398 & 1073 & 2978 \\
$03 / 02 / 2010$ & 947 & 12650 & 1350 & 2243 \\
$03 / 03 / 2010$ & 879 & 11349 & 935 & 2197 \\
\hline
\end{tabular}

were equilibrated for $24 \mathrm{~h}$ at constant humidity of $50 \%$ and temperature $\left(22^{\circ} \mathrm{C}\right)$ in the balance room before each weighing. A Po-210 (alpha emitter) electrostatic charge eliminator was used to eliminate the static charge accumulated on the filters before each weighing. The difference in weights for each filter was calculated and the mass concentrations for each $\mathrm{PM}_{10}$ or $\mathrm{PM}_{2.5}$ samples were determined.

The concentrations of $\mathrm{BC}$ in the $\mathrm{PM}_{10}$ and $\mathrm{PM}_{2.5}$ samples were determined by reflectance measurement in AECD laboratory using an Evans Electroselenium Limited (EEL) type Smoke Stain Reflectometer (Biswas et. al., 2003). Secondary standards of known black carbon concentrations were used to calibrate the reflectometer. The concentrations are defined based on the amount of reflected light that is absorbed by the filter sample and an assumed mass absorption coefficient. It is related to the concentration of light absorbing carbon through standards of carbon with known areal density. Iron $(\mathrm{Fe})$ has a moderate light absorption coefficient and can have some limited influence on the $\mathrm{BC}$ value measured by reflectance. The uncertainty associated with the $\mathrm{BC}$ measurement is rather high (4-9\%), and therefore, the influence of variation in $\mathrm{Fe}$ concentration on $\mathrm{BC}$ measurement has been neglected.

\section{Result and discussion}

The time series variation of the meteorological parameters and PM are shown in Fig.'s 2 and 3 respectively. It would be found that with the increase of wind speed and with rainfall, the PM values decrease. Again high humidity also helps to increase in size of fine particles and then easily remove from the environment.

The basic statistics of the concentration level are also illustrated in Table III. The difference between arithmetic mean and geometric mean is small suggesting minimum day-today variations in the data and perhaps major pollutants contributing to the PM pollution are from local sources. The 10

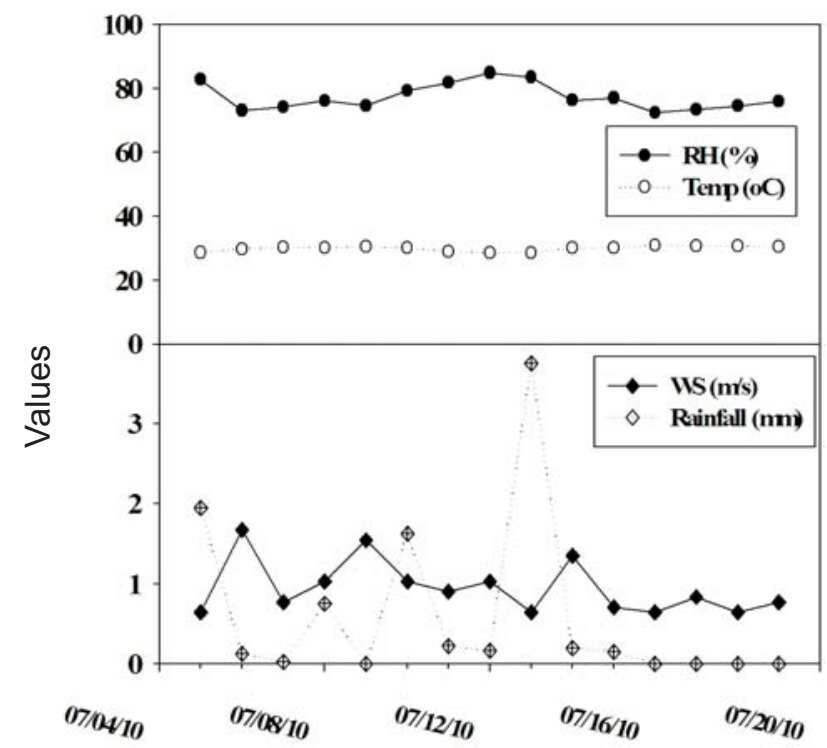

Fig. 2. Meteorological condition during the sampling time 


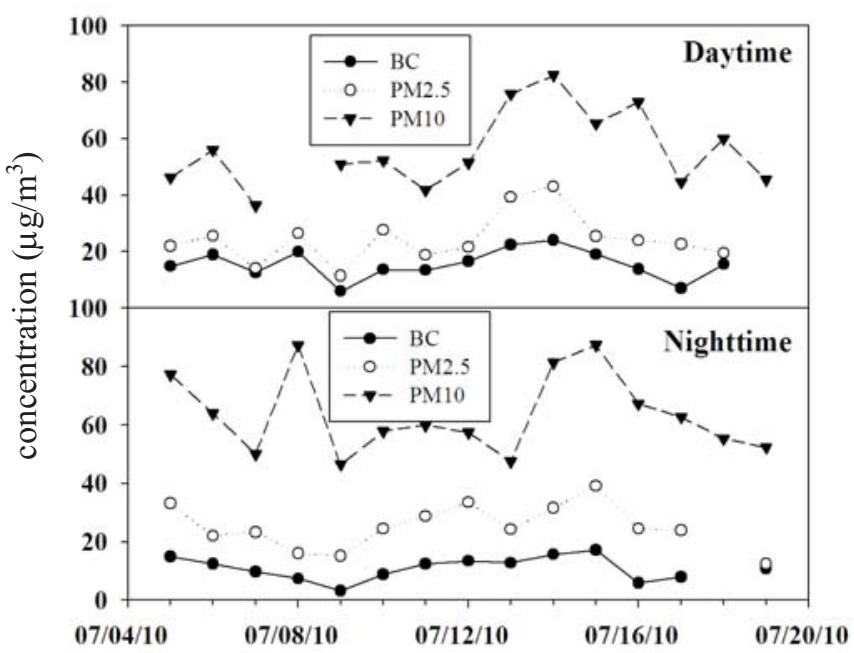

Fig. 3. Variation of $\mathbf{P M}_{10}, \mathbf{P M}_{2.5}$ and $\mathrm{BC}$ concentrations during the day and night time hr average values for both $\mathrm{PM}_{10}$ and $\mathrm{PM}_{2.5}$ masses (Table III) during day and night time are about 2.5 times less than the 24 hour average Bangladesh National Ambient Air Quality Standard as well as 1997 USEPA standards, which are set at $150 \mu \mathrm{g} / \mathrm{m}^{3}$ and $65 \mu \mathrm{g} / \mathrm{m}^{3}$ respectively.

It was found (Table IV) that the $\mathrm{PM}_{10}$ and $\mathrm{PM}_{2.5}$ concentrations between night time and day time are not remarkably different. This could be due to rainfall, which lower PM concentrations. The higher $\mathrm{PM}_{10}$ and $\mathrm{PM}_{2.5}$ concentrations observed at night may be attributed to heavy-duty diesel trucks that ply on the road, and the shopping markets, medical clinic and lot of small industries where the diesel generators run during the power failure in this area. Hence, the emissions from diesel vehicles and generators increase the $\mathrm{PM}_{2.5}$ concentrations, which in turn increase $\mathrm{PM}_{10}$ concentration.

Table III. The arithmetic mean and geometric mean of mass concentrations $\left(\mu \mathrm{g} / \mathrm{m}^{3}\right)$ during the study period

\begin{tabular}{lcccccc}
\hline Parameter & \multicolumn{3}{c}{ Day time } & \multicolumn{3}{c}{ Night time } \\
Average & $\mathrm{PM}_{10}$ & $\mathrm{PM}_{2.5}$ & $\mathrm{BC}$ & $\mathrm{PM}_{10}$ & $\mathrm{PM}_{2.5}$ & $\mathrm{BC}$ \\
95\% confidence interval & 55.8 & 24.4 & 15.6 & 63.6 & 25.2 & 10.9 \\
Geomean & $48.5-63.2$ & $11.8-37.0$ & $12.9-18.3$ & $56.5-70.7$ & $21.0-29.4$ & $8.85-13.0$ \\
95\% confidence interval & 54.3 & 23.1 & 14.6 & 62.3 & 24.0 & 10.1 \\
Max & $53.7-55.0$ & $22.4-23.8$ & $13.8-15.4$ & $61.6-62.9$ & $23.3-24.8$ & $9.29-10.9$ \\
Min & 82.5 & 43.1 & 24.1 & 87.3 & 39.1 & 17.2 \\
& 36.4 & 11.5 & 5.99 & 46.5 & 12.5 & 3.24 \\
\hline
\end{tabular}

Table IV. The direction of wind pattern with respect to day and $\mathbf{P M _ { 1 0 }}$ mass concentrations

\begin{tabular}{lccccc}
\hline Date & Wind Direction & \multicolumn{2}{c}{$\mathrm{PM}_{10} \mathrm{mass}\left(\mu \mathrm{g} / \mathrm{m}^{3}\right)$} \\
\cline { 2 - 5 } & & Day & Night & Day & Night \\
\hline $07 / 05 / 10$ & $\mathrm{SE}$ & 22.0 & 33.1 & 46.2 & 77.3 \\
$07 / 06 / 10$ & $\mathrm{~S}$ & 25.6 & 22.1 & 56.0 & 64.0 \\
$07 / 07 / 10$ & $\mathrm{~S}$ & 14.1 & 23.3 & 36.4 & 50.0 \\
$07 / 08 / 10$ & $\mathrm{~S}$ & 26.4 & 16.1 & 87.3 & 46.5 \\
$07 / 09 / 10$ & $\mathrm{~S}$ & 11.5 & 15.1 & 51.0 & 57.8 \\
$07 / 10 / 10$ & $\mathrm{~S}$ & 27.6 & 24.5 & 52.3 & 60.0 \\
$07 / 11 / 10$ & $\mathrm{SSE}$ & 18.8 & 28.8 & 41.8 & 57.5 \\
$07 / 12 / 10$ & $\mathrm{~S}$ & 21.6 & 33.5 & 51.5 & 47.5 \\
$07 / 13 / 10$ & $\mathrm{~S}$ & 39.3 & 24.3 & 75.8 & 81.3 \\
$07 / 14 / 10$ & $\mathrm{SE}$ & 43.1 & 31.6 & 82.5 & 87.3 \\
$07 / 15 / 10$ & $\mathrm{SE}$ & 25.5 & 39.1 & 65.3 & 67.3 \\
$07 / 16 / 10$ & $\mathrm{~S}$ & 24.0 & 24.5 & 73.0 & 62.6 \\
$07 / 17 / 10$ & $\mathrm{~S}$ & 22.6 & 24.0 & 44.6 & 52.3 \\
$07 / 18 / 10$ & $\mathrm{~S}$ & 19.5 & 60.0 & 55.3 & \\
$07 / 19 / 10$ & $\mathrm{~S}$ & & 12.5 & 45.5 & \\
\hline
\end{tabular}


Ratios of $B C / P M_{2.5}$ and $P M_{2.5} / P M_{10}$

Tables V and VI represent the variation of ratios of $\mathrm{BC} / \mathrm{PM}_{2.5}$ and $\mathrm{PM}_{2.5} / \mathrm{PM}_{10}$ during the winter and the rainy seasons. It was found that the concentration of $\mathrm{PM}_{2.5}$ and $\mathrm{PM}_{10}$ is about 5 times lower than the winter time. This may be due to meteorology, wind direction and rainfall. On the other hand, brick kilns are not in operation during the rainy season. Therefore, it has been found that the decrease of $\mathrm{PM}_{2.5}$ and $\mathrm{PM}_{10}$ is high compared to BC. The brick sector could not contribute to PM (high in $\mathrm{BC}$ ), as the brick sector is not operated in rainy season. From source apportionment results (Begum et. al., 2011a), it was found that the total mass concentration in wintertime is high and soil dust and road dust contribute about $60 \%$ of the total mass and in rainy season, it reduces to $33 \%$ of the total mass. Again as the wind mainly comes from south and southeast direction, therefore regional impact is less and there are sea salt contributions in the PM (both fine and coarse). The Hybrid Single Particle Lagrangian Integrated Trajectory (HYSPLIT 4) model (Draxler and Rolph, 2003) was used to calculate the air mass backward trajectories for days with high impacts of fine particles as

Table V. Comparison of $\mathrm{BC} / \mathrm{PM}_{2.5}$ and $\mathrm{PM}_{2.5} / \mathrm{PM}_{10}$ ratios at day time

\begin{tabular}{lccccc}
\hline Date & $\mathrm{BC} / \mathrm{PM}_{2.5}$ & $\mathrm{PM}_{2.5} / \mathrm{PM}_{10}$ & Date & ${\mathrm{BC} / \mathrm{PM}_{2.5}}$ & $\mathrm{PM}_{2.5} / \mathrm{PM}_{10}$ \\
\hline $02 / 17 / 10$ & 0.31 & 0.76 & $07 / 05 / 10$ & 0.68 & 0.48 \\
$02 / 18 / 10$ & 0.36 & 0.34 & $07 / 06 / 10$ & 0.74 & 0.46 \\
$02 / 19 / 10$ & 0.49 & 0.34 & $07 / 07 / 10$ & 0.90 & 0.39 \\
$02 / 20 / 10$ & 0.33 & 0.54 & $07 / 08 / 10$ & 0.75 & 0.22 \\
$02 / 21 / 10$ & 0.30 & 0.64 & $07 / 09 / 10$ & 0.52 & 0.53 \\
$02 / 22 / 10$ & 0.26 & 0.64 & $07 / 10 / 10$ & 0.49 & 0.45 \\
$02 / 23 / 10$ & 0.25 & 0.66 & $07 / 11 / 10$ & 0.71 & 0.42 \\
$02 / 24 / 10$ & 0.19 & 0.65 & $07 / 12 / 10$ & 0.77 & 0.52 \\
$02 / 25 / 10$ & 0.32 & 0.75 & $07 / 13 / 10$ & 0.57 & 0.52 \\
$02 / 26 / 10$ & 0.27 & 0.67 & $07 / 14 / 10$ & 0.56 & 0.39 \\
$02 / 27 / 10$ & 0.25 & 0.71 & $07 / 15 / 10$ & 0.75 & 0.51 \\
$02 / 28 / 10$ & 0.30 & 0.58 & $07 / 16 / 10$ & 0.57 & 0.32 \\
$03 / 01 / 10$ & 0.28 & 0.50 & $07 / 17 / 10$ & 0.31 & 0.80 \\
$03 / 02 / 10$ & 0.21 & 0.49 & $07 / 18 / 10$ & & \\
$03 / 03 / 10$ & 0.25 & 0.44 & $07 / 19 / 10$ & & \\
\hline
\end{tabular}

Table VI. Comparison of $\mathrm{BC} / \mathrm{PM}_{2.5}$ and $\mathrm{PM}_{2.5} / \mathrm{PM}_{10}$ ratios at night time

\begin{tabular}{lccccc}
\hline Date & $\mathrm{BC}_{\mathrm{PM}_{2.5}}$ & $\mathrm{PM}_{2.5} / \mathrm{PM}_{10}$ & Date & ${\mathrm{BC} / \mathrm{PM}_{2.5}}$ & $\mathrm{PM}_{2.5} / \mathrm{PM}_{10}$ \\
\hline $02 / 17 / 10$ & 0.29 & 0.84 & $07 / 05 / 10$ & 0.45 & 0.43 \\
$02 / 18 / 10$ & 0.40 & 0.57 & $07 / 06 / 10$ & 0.57 & 0.35 \\
$02 / 19 / 10$ & 0.33 & 0.62 & $07 / 07 / 10$ & 0.42 & 0.47 \\
$02 / 20 / 10$ & 0.37 & 0.69 & $07 / 08 / 10$ & 0.46 & 0.18 \\
$02 / 21 / 10$ & 0.38 & 0.65 & $07 / 09 / 10$ & 0.21 & 0.33 \\
$02 / 22 / 10$ & 0.36 & 0.72 & $07 / 10 / 10$ & 0.36 & 0.42 \\
$02 / 23 / 10$ & 0.26 & 0.80 & $07 / 11 / 10$ & 0.43 & 0.48 \\
$02 / 24 / 10$ & 0.35 & 0.99 & $07 / 12 / 10$ & 0.40 & 0.58 \\
$02 / 25 / 10$ & 0.26 & 0.56 & $07 / 13 / 10$ & 0.53 & 0.31 \\
$02 / 26 / 10$ & 0.26 & 0.55 & $07 / 14 / 10$ & 0.50 & 0.45 \\
$02 / 27 / 10$ & 0.24 & 0.82 & $07 / 15 / 10$ & 0.44 & 0.36 \\
$02 / 28 / 10$ & 0.25 & 0.62 & $07 / 16 / 10$ & 0.25 & 0.38 \\
$03 / 01 / 10$ & 0.28 & 0.55 & $07 / 17 / 10$ & 0.33 & \\
$03 / 02 / 10$ & 0.27 & 0.51 & $07 / 18 / 10$ & & 0.24 \\
$03 / 03 / 10$ & 0.24 & 0.63 & $07 / 19 / 10$ & 0.86 & \\
\hline
\end{tabular}


shown in Fig. 4. Backward trajectories starting at height of $500 \mathrm{~m}$ above the ground level were computed using the vertical mixing model. Fig. 4 shows the contribution on 13 and 14 July 2010 was likely due to contribution from southerly wind. The results indicate that PM concentrations in wet season are also influenced by southerly wind (Fig. 4). Therefore, we get sea salt contribution in PM samples. From Table IV, it can be found that most of the wind comes from South.

From Tables V and VI it may conclude that the background $\mathrm{PM}_{2.5}$ and $\mathrm{PM}_{10}$ concentrations in the urban ambient air in Dhaka city will be 24.8 and $59.7 \mu \mathrm{g} / \mathrm{m}^{3}$ (20h average) respectively. Hence the ambient air quality is much better in

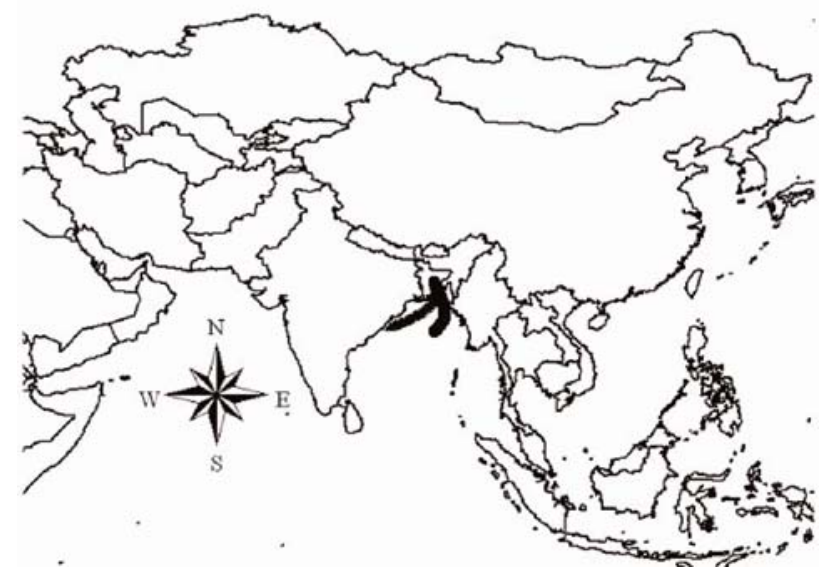

Fig. 4. Backward trajectories arriving Dhaka on 13 and 14 July 2010 computed at the NOAA Air Resources Laboratory HYSPLIT site

Dhaka during the wet season than the dry season when the rainfall and wind speed is minimal.

\section{Conclusion}

Bangladesh is a developing country and due to relatively faster economic growth, the numbers of industries especially around Dhaka city are increasing at a rapid pace. The population density is also increasing. To meet the growing transport demand, the numbers of vehicles are also increasing. The rate of increase is higher in and around Dhaka city and consequently has increased impact on the air quality. This impact is also reflected in the source apportionment results although majority of the vehicles currently running in Dhaka use compressed natural gas. There are also a large number of brick kilns operating surrounding the Dhaka city to meet the demand of the economic growth and the pollution from the brick kilns also increases day by day. From the present study, it is observed that the main criteria pollutant is particulate matter (PM) and the concentration of PM is compatible to the National Ambient Air Quality Standard (BNAAQS), Bangladesh. Although local sources of air pollution in Dhaka city are quite high in winter time, PM concentrations in wet season is about 2.5 times less than the daily ambient air quality standard.

\section{References}

Baldauf RW, Lane DD and Marotz GA (2001), Ambient Air Quality Monitoring Network Design for Assessing Human Health Impacts from Exposures to Airborne Contaminants, Environ. Monitoring and Assessment, 66: $63-76$.

Begum BA, Akhter S, Sarker L and Biswas SK (2006), Gravimetric analysis of Air Filters and Quality Assurance in Weighing, Nucl. Sci. and Appl. 15: 3641.

Begum BA, Biswas SK and Hopke PK (2011a), Key Issues in Controlling Air Pollutants in Dhaka Bangladesh, Atmos. Environ. 45: 7705-7713.

Begum BA, Biswas SK, Kim E, Hopke PK and Khaliquzzaman M (2005), Investigation of sources of atmospheric aerosol at a hot spot area in Dhaka, Bangladesh, J. Air and Waste Manage. Assoc. 55: 227240.

Begum BA, Biswas SK, Markwics A and Hopke PK (2010a), Identification of sources of fine and coarse particulate matter in Dhaka, Bangladesh, Aerosol and Air Quality Res. 10: 345-353.

Begum BA, Biswas SK, Pandit GG, Saradhib IV, Waheed S, Siddiquec N, Seneviratne MCS, Cohen DD, Markwics A and Hopke PK (2011b), Long Range Transport of Soil Dust and Smoke Pollution in the South Asian Region, Atmos. Poll. Res. 2: 151-157.

Begum BA, Kim E, Biswas SK and Hopke PK (2004)., Investigation of sources of atmospheric aerosol at urban and semi-urban areas in Bangladesh, Atmos. Environ. 38: 3025-3038.

Begum BA, Salahuddin KM, Hossain A, Sarwar G, Nasiruddin M, Biswas SK, Nahar N and Hopke PK 
(2012), Impact of vehicle fleet characteristics on ambient $\mathrm{PM}_{2.5}, \mathrm{PM}_{10}$ and Gas Concentrations in Dhaka at the Farm Gate (CAMS-2), J. Bangladesh Phys. Soc. 11: 89-102.

Biswas SK, Tarafdar SA, Islam A, Khaliquzzaman M, Tervahattu $\mathrm{H}$ and Kupiainen K (2003), Impact of unleaded gasoline introduction on the concentration of lead in the air of Dhaka, Bangladesh, J. Air and Waste Manage. Assoc. 53: 1355-1362.
Draxler RR and Rolph GD (2003), HYSPLIT 4(Hybrid Single-Particle Lagrangian Integrated Trajectory) Model access via NOAA ARL READY Website (http://www.arl.noaa.gov/ready/hysplit4.html). NOAA Air Resources Laboratory, Silver Spring, MD.

Salam A, Bauer H, Kassin K, Ullah SM and Puxbaum H (2003), Aerosol chemical characteristics of a mega-city in Southeast Asia (Dhaka, Bangladesh), Atmos. Environ. 37: 2517-2528.

Received: 21 May, 2013; Revised: 21 May 2013; Accepted: 09 June, 2013 